\title{
Cloning, Sequencing, and the Expression of the Elusive Sarcomeric TPM4 $\alpha$ Isoform in Humans
}

\author{
Dipak K. Dube, Syamalima Dube, Lynn Abbott, Ruham Alshiekh-Nasany, \\ Charles Mitschow, and Bernard J. Poiesz
}

Department of Medicine, SUNY Upstate Medical University, 750 East Adams Street, Syracuse, NY 13210, USA

Correspondence should be addressed to Bernard J. Poiesz; poieszb@upstate.edu

Received 31 May 2016; Revised 22 July 2016; Accepted 10 August 2016

Academic Editor: József Szeberényi

Copyright (C) 2016 Dipak K. Dube et al. This is an open access article distributed under the Creative Commons Attribution License, which permits unrestricted use, distribution, and reproduction in any medium, provided the original work is properly cited.

In mammals, tropomyosin is encoded by four known TPM genes (TPM1, TPM2, TPM3, and TPM4) each of which can generate a number of TPM isoforms via alternative splicing and/or using alternate promoters. In humans, the sarcomeric isoform(s) of each of the TPM genes, except for the TPM4, have been known for a long time. Recently, on the basis of computational analyses of the human genome sequence, the predicted sequence of TPM $4 \alpha$ has been posted in GenBank. We designed primer-pairs for RT-PCR and showed the expression of the transcripts of TPM $4 \alpha$ and a novel isoform TPM $4 \delta$ in human heart and skeletal muscle. qRT-PCR shows that the relative expression of TPM $4 \alpha$ and TPM $4 \delta$ is higher in human cardiac muscle. Western blot analyses using CH1 monoclonal antibodies show the absence of the expression of TPM $4 \delta$ protein $(\sim 28 \mathrm{kDa})$ in human heart muscle. $2 \mathrm{D}$ western blot analyses with the same antibody show the expression of at least nine distinct tropomyosin molecules with a mass $\sim 32 \mathrm{kD}$ and above in adult heart. By Mass spectrometry, we determined the amino acid sequences of the extracted proteins from these spots. Spot "G" reveals the putative expression of TPM $4 \alpha$ along with TPM1 $\alpha$ protein in human adult heart.

\section{Introduction}

Tropomyosin (TPM) is a coiled-coil dimer protein that plays important role(s) in regulating muscle contraction in conjunction with other sarcomeric proteins like actin, troponins, tropomodulin, and so forth. TPM also provides structural stability to actin filaments, thereby modulating cytoskeleton function. In vertebrates, there are four TPM genes, designated as TPM1, TPM2, TPM3, and TPM4, except for zebrafish where six TPM genes are present [1-10]. Each of the four genes generates a large number of TPM isoforms via alternative splicing and/or using different promoters. In mammals, the exon and intron organization of TPM genes are very similar, if not identical [6]. The rodent TPM4 gene has lost the use of exons la and 2; the high molecular weight isoforms encoding 284 amino acid residues such as TPM $4 \alpha$ and TPM $4 \beta$ are not expressed as they are in nonmammalian species. It was speculated for a long time that the TPM4 gene in humans as in rodents does not encode sarcomeric isoform with exon $9 a / b[2,3]$. The first report on the expression of a high molecular weight TPM4 protein was reported in human ovary tumor tissues in 2004 (accession number AK023385). This isoform, defined as TPM $4 \beta$, contains exons 1a, 2, 3, 4, 5, $6,7,8$, and $9 \mathrm{~d}$ (Figure 1), which differs from the sarcomeric TPM $4 \alpha$ isoform containing exon $9 \mathrm{a} / \mathrm{b}$ instead of $9 \mathrm{~d}$. It is to be noted that exon 9a but not $9 \mathrm{~d}$ encodes the peptide that is essential for binding TPM with troponins $[2,3]$, essential components of thin filament. Recently, two predicted sequences (derived from a genomic sequence) of the two different isoforms of the human TPM4 gene containing exon 9 a have been reported in GenBank (on March 12, 2015). One of the predicted isoforms is TPM $4 \alpha$ (as in avian and amphibians) containing exons 1a, 2, 3, 4, 5, 6b, 7, 8, and 9a/b encoding 284 amino acids (accession number XM_006722865). The other one may encode a low molecular weight novel protein with 248 amino acids consisting of exons $1 \mathrm{~b}, 3,4,5,6,7,8$, and 9a/b (accession number XM_005260042.2). In this study, for the first time we confirmed the expression of these two new transcripts, viz TPM $4 \alpha$ (or Tpm $4.3(8)$ ) and TPM $4 \delta$ (Tpm 4.4 (8)) by RT-PCR with the RNA from human adult heart, fetal heart, and skeletal muscle using two primer-pairs designed from the predicted nucleotide sequences. We confirmed 


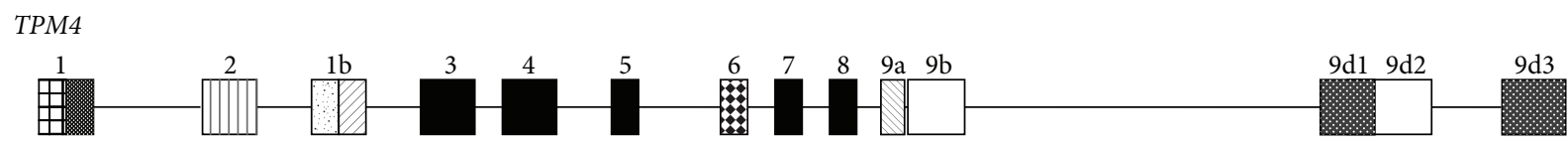

TPM4 $\alpha$ (or Tpm 4.3)

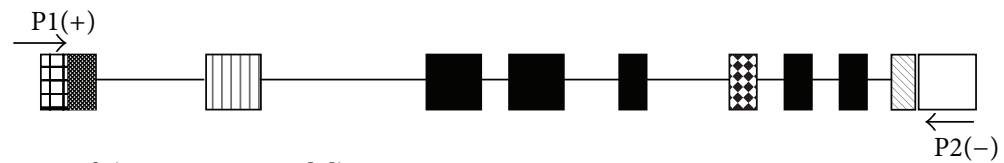

TPM4 $\beta$ (or Tpm 4.1 as in [7])

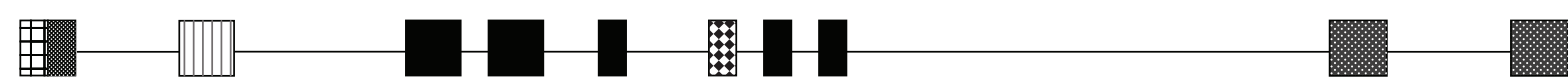

TPM4 $\gamma$ (or Tpm 4.2 as in [7])

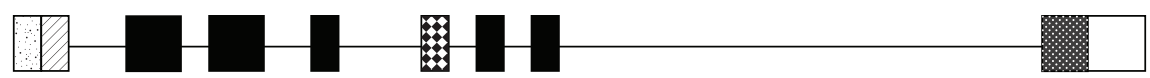

TPM4 $\delta$ (or Tpm 4.4)

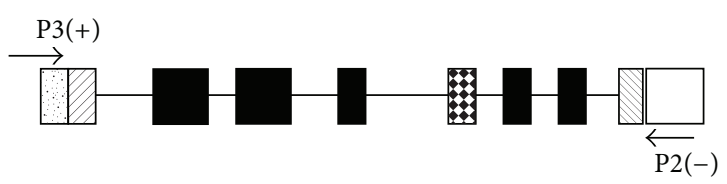

FIGURE 1: Alternative splicing pattern of the TPM4 gene in humans. Exon composition of the TPM4 gene is derived from the published documents (top) and the recently submitted data in GenBank. Although the splice variants TPM4 $\beta$ (NM_001145160) and TPM4 $\gamma$ (NM003290.2) are known for some time, the cartoons of the splice variants of TPM4 $\alpha$ and TPM $4 \delta$ are generated with the information of the recently submitted sequences of the corresponding predicted isoforms in GenBank as well as the results from the present study. Exon locations of primers $\mathrm{P} 1(+), \mathrm{P} 2(-)$, and $\mathrm{P} 3(+)$ are shown.

the sequences of both the isoforms by cloning and sequencing of the amplified products. We also determined the relative expression of the two transcripts by qRT-PCR with RNA from human adult heart, fetal heart, and skeletal muscle using isoform specific primer-pairs. For protein expression, we performed $1 \mathrm{D}$ and $2 \mathrm{D}$ western blot analyses with the extract from adult human heart using the exon 9a-specific monoclonal antibody, CH1. We found nine spots on western blot and the protein was extracted from the spots for mass spectrometry (LC-MS/MS) analyses. The results suggest that spot G may have TPM $4 \alpha$ along with TPM1 $\alpha$ protein. To the best of our knowledge, this is the first report of TPM $4 \alpha$ protein expression in humans.

\section{Materials and Methods}

Human adult and fetal cardiac tissue RNA were obtained from Zyagen (San Diego, CA); adult human heart protein samples were obtained from Imgenex (San Diego, CA).

2.1. Conventional RT-PCR. All PCR and post-PCR experiments were done by different personnel in in different buildings using separate equipment and separate ventilation so as to avoid carryover contamination. For RT-PCR, $0.5 \mu \mathrm{g}$ of RNA in a total volume of $40 \mu \mathrm{L}$ was used to synthesize cDNA with SuperScript ${ }^{\circledR}$ II (Life Technologies, Grand Island, NY) and oligo-dT primers following the manufacturer's specifications. For each PCR $3 \mu \mathrm{L}$ of cDNA was used and
TPM $4 \alpha$ and TPM4 $\delta$ RNA were amplified as previously described $[11,12]$. The nucleotide sequences of the primerpairs for amplification of TPM $4 \alpha$ and TPM $4 \delta$ are given in Table 1. It is to be noted that the negative primer for amplification of TPM $4 \alpha$ and TPM $4 \delta$ is the same. The positive primers for TPM $4 \alpha$ and TPM4d are from exon 1a and exon $1 b$, respectively. The PCR amplified DNAs were run in an agarose gel and the ethidium bromide stained bands were excised from the gel and DNA was extracted from the excised bands using a MinElute Gel extraction kit from Qiagen (Valencia, CA) following the manufacturer's direction. Part of the DNA was used for sequencing and part of the gel extracted DNAs was ligated and cloned into the T/A cloning vector (Life Technologies) following our published protocol $[11,12]$. Positive clones were identified by PCR using the above-mentioned specific primer-pairs previously described. Vectors or constructs were grown in E. coli, and the DNA was extracted using Qiagen Miniprep kit (Valencia, CA). The isolated DNA was sequenced (Cornell University Life Science Core Laboratories Center, Ithaca, NY). Each clone was sequenced twice in both directions. It is to be noted that the primer-pair we have used for TPM $4 \alpha$ and TPM $4 \delta$ is very specific for the respective isoform.

2.2. Real-Time Quantitative RT-PCR. qRT-PCR analysis of cDNA template was performed using the LightCycler 480 Real-Time PCR System. Reactions were carried out in a 384well plate using the LightCycler 480 SYBR Green I Master kit 
TABLE 1: Nucleotide sequences of the primer-pairs used for conventional and qRT-PCR analyses.

\begin{tabular}{|c|c|c|c|}
\hline Primer & Isoform & Type of PCR & Sequence \\
\hline TPM4 $\alpha-\mathrm{F}-1(\mathrm{P} 1+)$ & TPM $4 \alpha$ & $\begin{array}{c}\text { Both conventional } \\
\text { \& qRT-PCR }\end{array}$ & $5^{\prime}$-CAGCCATGGAGGCCATCAAGA-3' \\
\hline TPM4 $\alpha-\mathrm{R}-1(\mathrm{P} 2-)$ & TPM $4 \alpha$ & Conventional & $5^{\prime}$-CACCATGTGAGAAGGACAGA-3' \\
\hline TPM $4 \alpha-\mathrm{R}-2$ & ТРМ $4 \alpha$ & qRT-PCR & 5'-ACGAGCTGGATGCGTCGGT-3' \\
\hline TPM4 $\delta$-F-1 (P3+) & TPM $4 \delta$ & $\begin{array}{l}\text { Conventional } \\
\text { \& qRT-PCR }\end{array}$ & $5^{\prime}$-ATGGCCGGCCTCAACTCCCTGG-3' \\
\hline TPM4d-R-1 & TPM4d & Conventional & $5^{\prime}$-CACCATGTGAGAAGGACAGA-3' \\
\hline TPM4d-R-2 & TPM4d & qRT-PCR & 5'-ACGAGCTGGATGCGTCGGT-3' \\
\hline 18s rRNA-F & 18s rRNA & qRT-PCR & $5^{\prime}$-TGCTGCAGTTAAAAAGCTCGTA-3' \\
\hline 18s rRNA-R & 18 s rRNA & qRT-PCR & 5-ACCAACAAAATAGAACCGCGG-3' \\
\hline
\end{tabular}

TABLE 2: Key to 2D gel loading and sample preparation. The sample was lyophilized and redissolved to $4 \mathrm{mg} / \mathrm{mL}$ in 1:1 diluted SDS boiling buffer : urea sample buffer before loading.

\begin{tabular}{lcccc}
\hline Gel ID \# & Sample & $\mu$ L loaded & $\mu$ loaded & Treatment \\
\hline LF975 \#1 & HT-801 Zyagen Human Heart & 150 & 500 & Coomassie \\
LF975 \#2 & HT-801 Zyagen Human Heart & 150 & 500 & Antitropomyosin \\
\hline
\end{tabular}

(Roche). Briefly, each well contained a total volume of $10 \mu \mathrm{L}$ reaction solution, of which $2 \mu \mathrm{L}$ was.

cDNA template and $8 \mu \mathrm{L}$ were SYBR green mix $(5 \mu \mathrm{L}$ 1x SYBR green master mix, $2.8 \mu \mathrm{L}$ of PCR-grade water, and $0.2 \mu \mathrm{L}$ of $10 \mu \mathrm{M}$ primer-pair). Primers for real-time PCR for TPM $4 \alpha$ and TPM $4 \delta$ are listed in Table 1.

In this case cDNA was made with an oligonucleotide from exon 9a/b (5'-CACCATGTGAGAAGGACAGA-3') that allowed us to make a gene specific cDNA corresponding to the mRNA containing exon $9 / \mathrm{b}$ as in TPM $4 \alpha$ and TPM $4 \delta$ and would avoid any subsequent nonspecific PCR amplification. For the amplification of TPM $4 \alpha$ and TPM $4 \delta$, we have employed the positive primers from exon la and exon $1 b$, respectively, and the same negative primer located in exon 3. Amplification in the absence of cDNA template was also evaluated to insure a lack of signal due to primer dimerization and extension or carryover. All samples and controls were performed in triplicate. Data were analyzed using deltadelta CT (sample delta CT minus comparator delta CT) methods [13-15]. Efficiencies (E) of PCR amplification were determined using dilution series of plasmids and/or human heart cDNAs generated with gene specific primer-pairs as described by Nan et al. [16]. As a result, the primer-pair we have used from each of the isoforms is very specific and does not amplify other isoforms generated from the TPM4 or any other TPM gene.

2.3. Western Blot. $10 \mu \mathrm{g}$ of protein from each sample (human adult and fetal heart) was used for western blot analyses following our published protocol [17]. Primary antibodies included TM311 (Sigma-Aldrich, St. Louis, MO) and $\mathrm{CH} 1$ antisarcomeric tropomyosin (DSHB, University of Iowa, Iowa). Secondary antibody was sheep antimouse immunoglobulin HRP (GE Healthcare Bio-Sciences, Pittsburgh, PA).
2.4. 2D Western Blot and Mass Spectrometry. 2D (twodimensional) western blot analyses of the commercial human adult heart extract obtained from Zyagen (San Diego, CA) were performed for us by Kendrick Labs, Inc. (Madison, WI). Two-dimensional electrophoresis was performed according to the carrier ampholine method of isoelectric focusing [18, 19] by Kendrick Labs, Inc. (Madison, WI) as described by Wang et al. [20]. The key to 2D Gel loading and sample preparation is given in Table 2. The Coomassie blue-stained PVDF membrane was desktop scanned, destained in 100\% methanol, rinsed briefly in Tween-20 Tris-buffered saline (TTBS), and blocked for two hours in 5\% nonfat dry milk (NFDM) in TTBS. The blot was incubated in primary antibody (Anti-Tropomyosin-Clone CH1 (Developmental Studies Hybridoma Bank) diluted 1:10,000 in 2\% NFDM TTBS) overnight and rinsed $3 \times 10$ minutes in TTBS. The blot was placed in secondary antibody (antimouse IgG-HRP (GE Healthcare, Cat number NA931V, Lot number 9621358) diluted $1: 2,000$ in 2\% NFDM TTBS) for two hours, rinsed as above, treated with ECL, and exposed to X-ray film. For the developed X-ray film when superimposed on the Coomassie stained human adult heart protein gel, 9 spots (A-I) were exhibited (as in Figure 7(a)). Nine gel spots were excised, washed, and trypsinized following the published protocols [21-23]. The resulting peptides were extracted twice with 5\% formic acid/50 mM ammonium bicarbonate/50\% acetonitrile and once with $100 \%$ acetonitrile under moderate shaking. The peptide mixture was then dried in SpeedVac, solubilized in $20 \mu \mathrm{L}$ of $0.1 \%$ formic acid $/ 2 \%$ acetonitrile.

2.5. $L C-M S / M S$. The peptides mixture was analyzed by reverse phase liquid chromatography (LC) and MS (LCMS/MS) using a nanoACQUITY UPLC (Micromass/Waters, Milford, MA) coupled to a Q-TOF Ultima API MS (Micromass/Waters, Milford, MA), according to published procedures [22-24]. Briefly, the peptides were loaded onto a $100 \mu \mathrm{m}$ 


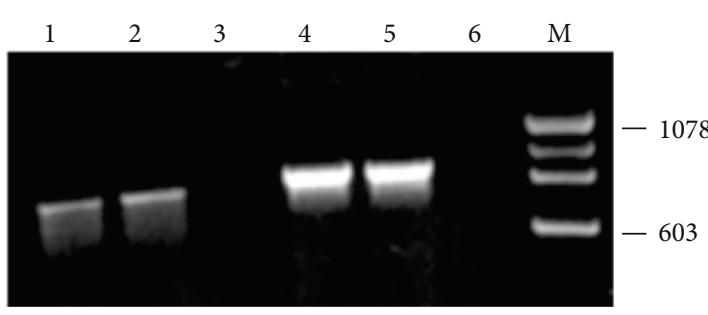

(a)

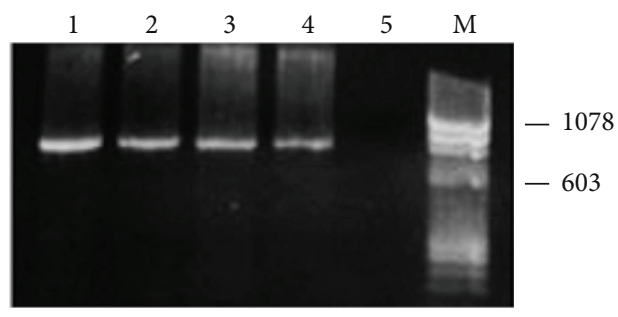

(b)

FIgURE 2: Expression of TPM4 isoforms with exon 9a/b in human heart and skeletal muscle by conventional RT-PCR. (a) Expression of $T P M 4 \alpha$ and TPM $\delta$ in human fetal and adult hearts as determined. TPM4 $\delta$ amplified with primer $1(+)$ and primer 2(-) as shown in Figure 1 and Table 1 . The size of the amplified DNA is $\sim 747 \mathrm{bp}$. Lane 1: adult heart; lane 2: fetal heart; lane 3: primer control. TPM4 $\alpha$ amplified with primer $1(+)$ and primer 2(-) as shown in Figure 1 and Table 1 . The size of the amplified DNA is $~ 855 \mathrm{bp}$. Lane 4: adult heart; lane 5: fetal heart; lane 6: primer control. (b) Expression of TPM4 $\alpha$ in human fetal heart, adult heart, and adult skeletal muscle. TPM4 $\alpha$ amplified with primer $1(+)$ and primer 2(-) as shown in Figure 1 and Table 1 . The size of the amplified DNA is $\sim 855 \mathrm{bp}$. Lane 1: fetal heart; lane 2: adult heart; lane 3: adult skeletal muscle (source 1); lane 4: adult skeletal muscle (source 2); lane 5: primer control.

$\times 10 \mathrm{~mm}$ nanoACQUITY BEH130 C18 $1.7 \mu \mathrm{m}$ UPLC column (Waters, Milford, MA) and eluted over a 150-minute gradient of $2-80 \%$ organic solvent (ACN containing $0.1 \%$ FA) at a flow rate of $400 \mathrm{~nL} / \mathrm{min}$. The aqueous solvent was $0.1 \% \mathrm{FA}$ in HPLC water. The column was coupled to a PicoTip Emitter SilicaTip nanoelectrospray needle (New Objective, Woburn, MA). MS data acquisition involved survey MS scans and automatic data dependent analysis (DDA) of the top three ions with the highest intensity ions with the charge of $2+, 3+$, or $4+$ ions. The MS/MS was triggered when the MS signal intensity exceeded 10 counts/second. In survey MS scans, the three most intense peaks were selected for collisioninduced dissociation (CID) and fragmented until the total MS/MS ion counts reached 10,000 or for up to 6 seconds each. The entire procedure used was previously described [22-24]. Calibration was performed for both precursor and product ions using 1 pmol GluFib (Glu1-Fibrinopeptide B) standard peptide with the sequence EGVNDNEEGFFSAR and the monoisotopic doubly charged peak with $m / z$ of 785.84 .

2.6. Data Processing and Protein Identification. The raw data were processed using ProteinLynx Global Server (PLGS, version 2.4) software as previously described by Darie et al. [22].

\section{Results}

3.1. Detection of RNA Expression by RT-PCR and Cloning and Sequencing of TPM $4 \alpha$ and TPM $4 \delta c D N A s$. In order to detect the expression of TPM $4 \alpha$ and TPM $4 \delta$ in human striated muscles, we used conventional RT-PCR with the RNA from adult human heart and skeletal muscles. The primer-pairs were designed from the predicted sequences as reported in the GenBank (accession number XM_006722865.1 for TPM $4 \alpha$ and XM_005260042.2 for TPM4 $\delta$ ). The nucleotide sequences of the primer-pairs designed are presented in Table 1 .

Conventional RT-PCR results presented in Figure 2(a) show that TPM $4 \delta$ is expressed in both fetal (lane 1) and adult human heart (lane 2).
Also, the TPM $4 \alpha$ is expressed in both fetal and adult heart as depicted in lanes 4 and 5, respectively. Again, TPM4a is expressed in fetal heart (lane 1, Figure 2(b)), adult heart (lane 2, Figure 2(b)), and also skeletal muscle (lanes 3 and 4 representing two different sources of adult human skeletal muscle RNA).

The amplified DNA from the ethidium stained band(s) on agarose gel was extracted and purified using a gel extraction kit from Ambion, Inc. Gel extracted DNA was used subsequently for nucleotide sequence determination as well as cloning into T/A cloning vector (Invitrogen). Direct DNA sequence analyses confirmed the expression of TPM $4 \alpha$ and TPM $4 \delta$ in both heart and skeletal muscle. DNA sequencing was also performed with the cDNA of each TPM4 isoform cloned in T/A cloning vector. Figures 3 and 4 depict the nucleotide as well as deduced amino acid sequences of TPM $4 \alpha$ and TPM $4 \delta$. The sequences are identical with the predicted sequences as submitted in GenBank. When the amino acid sequences of TPM $4 \alpha$ and TPM1 $\alpha$ (Acc number NP_001018005) are compared, there are 96.127 percent similarity and 88.028 percent identity between the two sarcomeric isoforms (best fit results not shown). To the best of our knowledge this is the first report on the expression of TPM $4 \alpha$ and TPM $4 \delta$ in human striated muscles. Comparisons of the amino acid sequences of TPM $4 \delta$ and the known TPM4 $\gamma$ indicate that both isoforms encode a 248amino acid polypeptide with identical sequences except for exon 9. The exon compositions of TPM $4 \gamma$ and TPM $4 \delta$ are given in Figure 1. TPM4 $\gamma$ contains exons $1 \mathrm{~b}, 3,4,5,6 \mathrm{~b}, 7,8$, and $9 \mathrm{~d}$ while TPM $4 \delta$ contains exon $9 \mathrm{a}$ instead of $9 \mathrm{~d}$.

3.2. qRT-PCR Analyses to Determine the Relative Expression of TPM4 $\alpha$ and TPM4S in Human Fetal Heart, Adult Heart, and Adult Skeletal Muscle. The results depicted in Figures 5 and 2(b) confirm that TPM $4 \alpha$ is expressed in human hearts and skeletal muscle. Interestingly, the expression level of both isoforms is the least in skeletal muscle. However, the relative expression of TPM $4 \alpha$ and TPM $4 \delta$ is higher in fetal heart compared to adult heart and adult skeletal muscle. The results also indicate that the relative expression of TPM $4 \alpha$ is much 

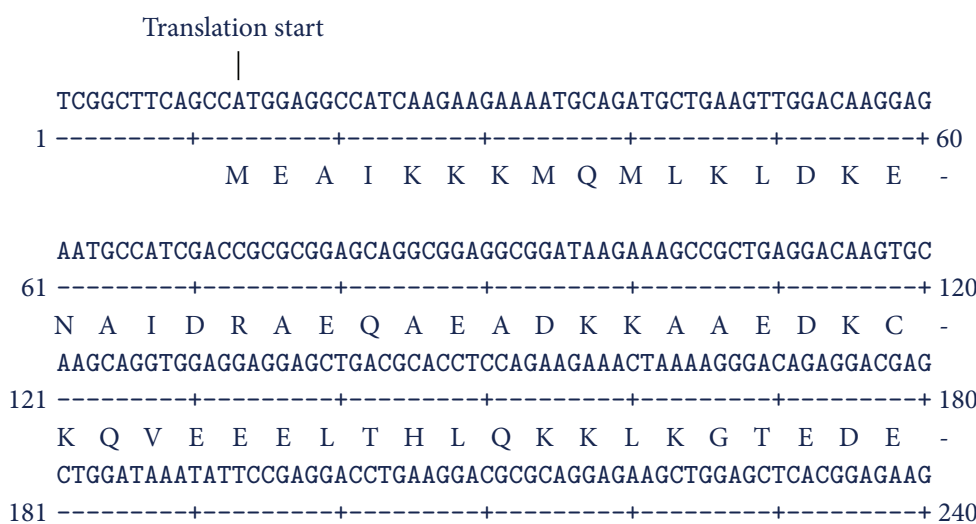

$\begin{array}{lllllllllllllllllllll}\mathrm{L} & \mathrm{D} & \mathrm{K} & \mathrm{Y} & \mathrm{S} & \mathrm{E} & \mathrm{D} & \mathrm{L} & \mathrm{K} & \mathrm{D} & \mathrm{A} & \mathrm{Q} & \mathrm{E} & \mathrm{K} & \mathrm{L} & \mathrm{E} & \mathrm{L} & \mathrm{T} & \mathrm{E} & \mathrm{K} & -\end{array}$ AAGGCCTCCGACGCTGAAGGTGATGTGGCCGCCCTCAACCGACGCATCCAGCTCGTTGAG

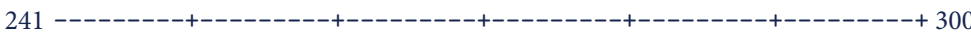

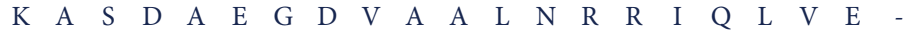
GAGGAGTTGGACAGGGCTCAGGAACGACTGGCCACGGCCCTGCAGAAGCTGGAGGAGGCA

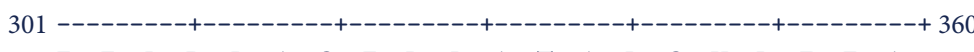

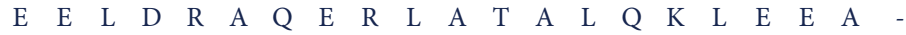
GAAAAAGCTGCAGATGAGAGTGAGAGAGGAATGAAGGTGATAGAAAACCGGGCCATGAAG

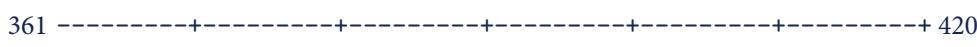

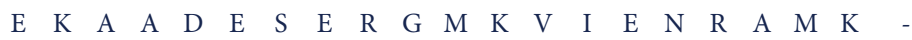
GATGAGGAGAAGATGGAGATTCAGGAGATGCAGCTCAAAGAGGCCAAGCACATTGCGGAA

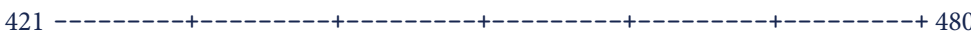

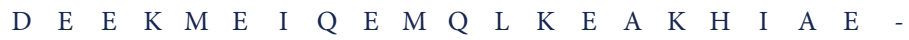
GAGGCTGACCGCAAATACGAGGAGGTAGCTCGTAAGCTGGTCATCCTGGAGGGTGAGCTG

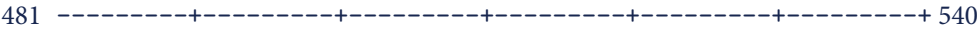

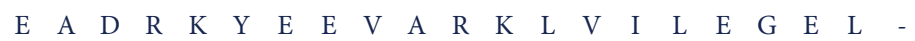
GAGAGGGCAGAGGAGCGTGCGGAGGTGTCTGAACTAAAATGTGGTGACCTGGAAGAAGAA

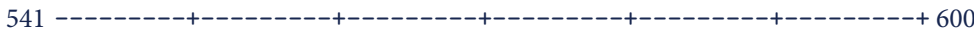

$\begin{array}{lllllllllllllllllllllllllllllllllll} & \text { E } & R & A & E & E & R & A & E & V & S & E & L & K & C & G & D & L & E & E & E & -\end{array}$ CTCAAGAATGTTACTAACAATCTGAAATCTCTGGAGGCTGCATCTGAAAAGTATTCTGAA

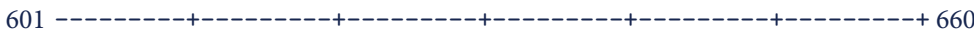

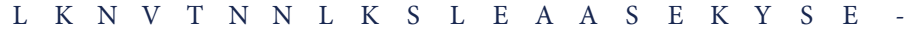
AAGGAGGACAAATATGAAGAAGAAATTAAACTTCTGTCTGACAAACTGAAAGAGGCTGAG

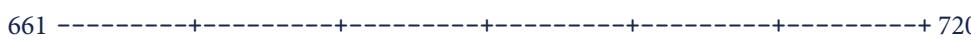

$\begin{array}{lllllllllllllllllllllllllllllllllllll}K & E & D & K & Y & E & E & E & I & K & L & L & S & D & K & L & K & E & A & E & -\end{array}$ ACCCGTGCTGAATTTGCAGAGAGAACGGTTGCAAAACTGGAAAAGACAATTGATGACCTG

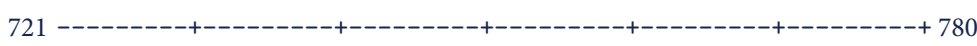

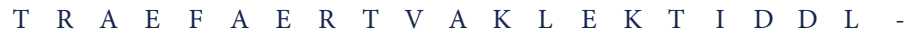
GAAGATGAGTTATACGCTCAGAAGCTCAAGTACAAAGCTATCAGCGAGGAACTGGACCAC

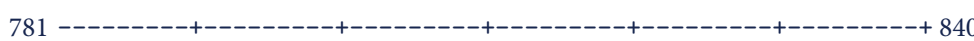

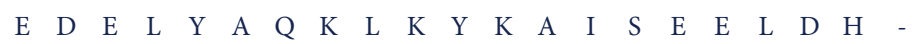
GCTCTCAACGACATGACCTCTCTCTGAGAGGCAGCCAGGTCGCTGCCCTCTGTCCTTCTC

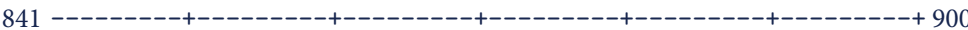

$\begin{array}{lllllllllllllll}\text { A } & \text { L } & \text { N } & \text { D } & \text { M } & \text { T } & S & \text { L } & *\end{array}$

Human TMP $4 \alpha$

FIGURE 3: Nucleotide and deduced amino acid sequences of human TPM4 $\alpha$. Deduced amino acid sequences are at the bottom of the nucleotide sequences. Symbol of each amino acid residue is placed at the bottom of the first nucleotide of each codon. * signifies Stop codon.

higher compared to TPM $4 \delta$ in all the tissues tested. Please note the difference in scale for TPM $4 \alpha$ and TPM $4 \delta$ shown in Figure 5.

3.3. Western Blot Analyses with the Total Protein Extracts of Human Adult Heart. In order to explore whether or not $\mathrm{TPM} 4 \alpha$ and TPM $4 \delta$ proteins are expressed in human striated muscles, we have employed western blot analyses with the $\mathrm{CH} 1$ monoclonal antibody that recognizes an epitope in exon 9a. In other words, $\mathrm{CH} 1$ monoclonal antibody recognizes all known sarcomeric TPM isoforms (TPM $\alpha$, TPM1 $\kappa$, TPM $2 \alpha$, $\mathrm{TPM} 3 \alpha$, and TPM $4 \alpha$ ) and the nonsarcomeric TPM $4 \delta$ having a peptide encoded by exon $9 \mathrm{a}$ at the C-terminus end. Each of these sarcomeric isoforms contains 284 amino acids and 


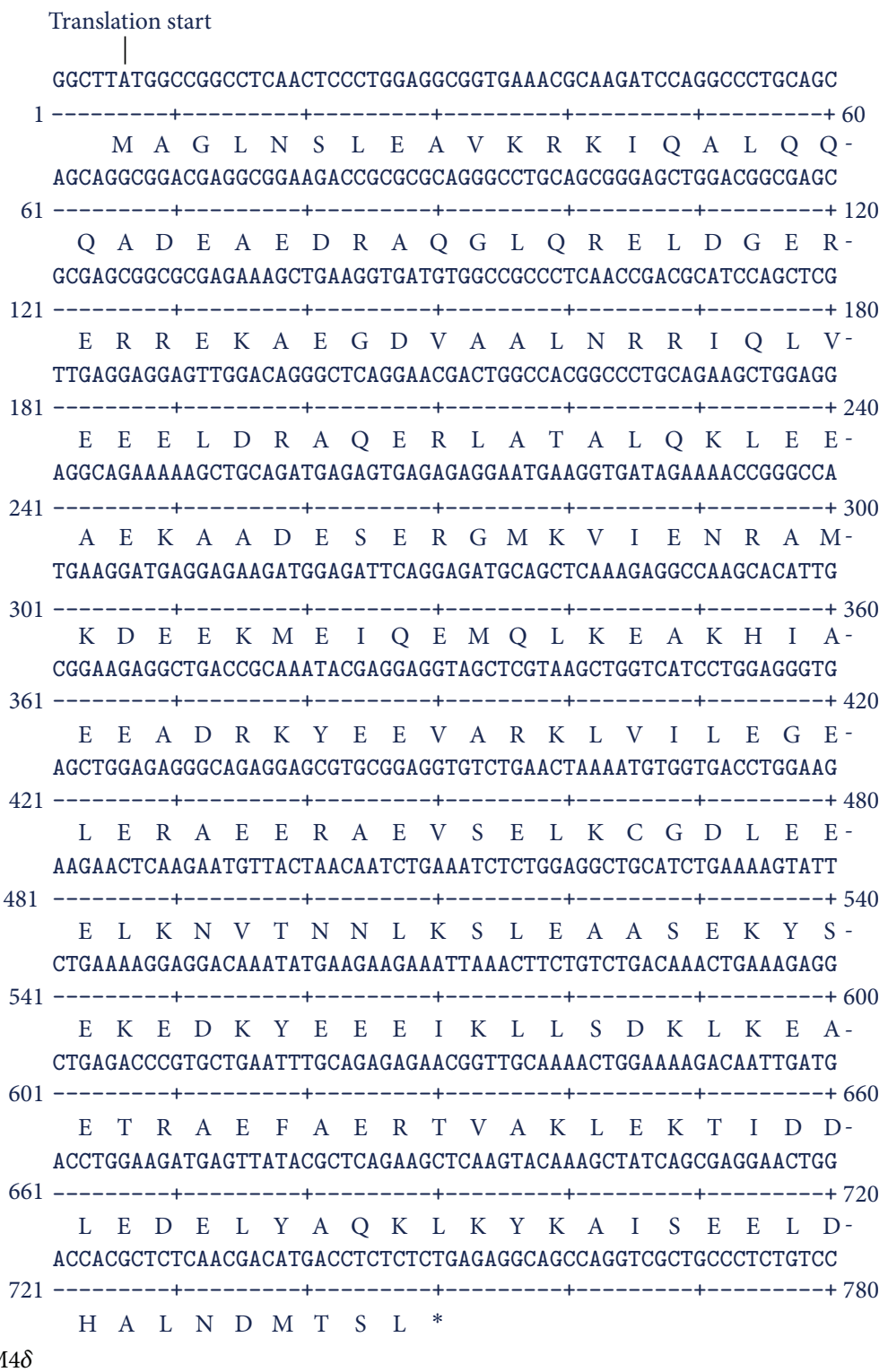

FIgURE 4: Nucleotide and deduced amino acid sequences of human TPM4 $\delta . *$ signifies Stop codon.

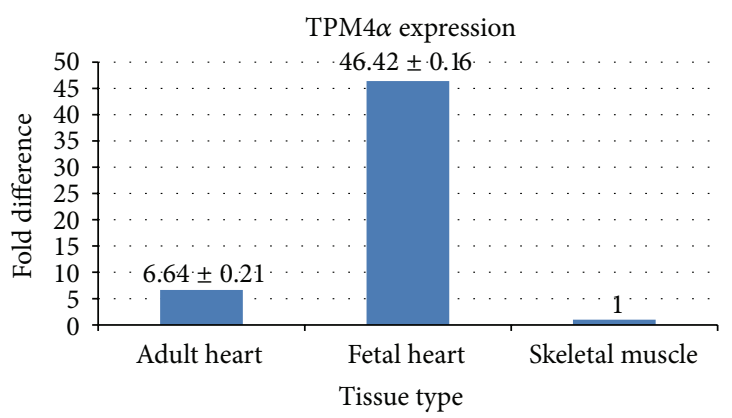

(a)

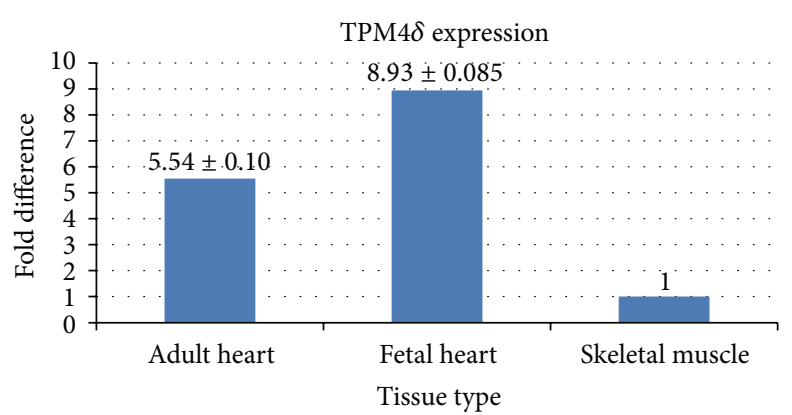

(b)

FIGURE 5: Relative expression of TPM $4 \alpha$ and TPM $4 \delta$ in human adult and fetal hearts. Fold changes of TPM $4 \alpha$ and TPM $4 \delta$ in human adult heart, fetal heart, and skeletal muscle. qRT-PCR was carried out in triplicate with isoform specific primer-pairs sequences of which are given in Table 1. (a) TPM $4 \alpha$ and (b) TPM $4 \delta$. 


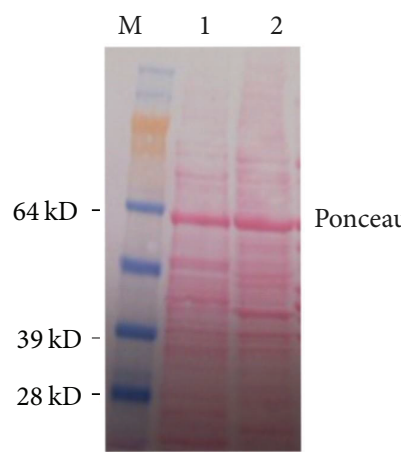

(a)

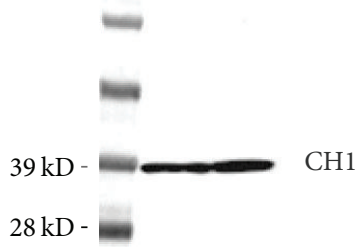

(b)

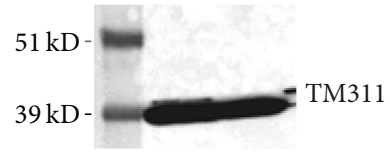

(c)

Figure 6: Western blot analysis of protein extracts from human adult and fetal hearts with CH1 and TPM311 antitropomyosin antibodies. (a) Ponceau-stained blot: lane 1: extract of adult heart; lane 2: extract of fetal heart; lane M: molecular weight markers. (b) Blots stained with $\mathrm{CH} 1$ monoclonal antibodies that recognize all sarcomeric TPM isoforms as well as TPM $4 \delta$ with exon 9a Cterminus end. (c) Blot stained with TM311 monoclonal antibodies that recognize all high molecular wt TPM isoforms with exon la at the N-terminus end. However, it does not recognize TPM $4 \delta$ with exon $\mathrm{lb}$ at the $\mathrm{N}$-terminus end.

is considered as high molecular wt tropomyosin. Although TPM $4 \delta$ encodes 248 amino acids and has different exon 1 , exon 9 is identical to TPM $4 \alpha$. Hence, if TPM $4 \delta$ protein is expressed, one should observe a signal at the $\sim 28 \mathrm{kDa}$ region in the western blot. We have employed another monoclonal antitropomyosin antibody TM311, which recognizes all high molecular wt tropomyosin molecules $(\sim 32 \mathrm{kDa}$ and above) containing exon la. As TPM4 $\delta$, unlike TPM $4 \alpha$, contains exon $1 \mathrm{~b}$ instead of exon la, one should not observe any $\sim 28 \mathrm{kDa}$ signal with TM311 antibodies. The results depicted in Figure 6 (staining with $\mathrm{CH} 1$ monoclonal antibodies) show strong signal(s) at $\sim 39 \mathrm{kDa}$ region. The results show the presence of most likely several sarcomeric isoforms, for example, TPM1 $\alpha$, TPM1 $\kappa$, TPM2 $\alpha$, and TPM $3 \alpha$, in human hearts. Without using a TPM4 specific antibody one cannot infer that the signal(s) at the $\sim 39 \mathrm{kDa}$ region indicates the presence of $\mathrm{TPM} 4 \alpha$ protein in human cardiac muscles. In addition, we did not detect the presence of low molecular wt tropomyosin like TPM4 $\delta$. If it was expressed in detectable quantity, we should have picked up a signal. Western blot analyses with TM311 confirm the expression of high molecular wt sarcomeric and nonsarcomeric TPM isoforms in adult and fetal heart tissues. TM311 should not recognize low molecular wt TPM $4 \delta$, which contains exon $1 \mathrm{~b}$ rather than exon la region [6].

3.4. 2D Western Blot Analyses with Protein Extracts of Adult Human Heart with CH1 Monoclonal Antibody That Recognizes
All Sarcomeric Tropomyosin Isoforms including TPM4a and

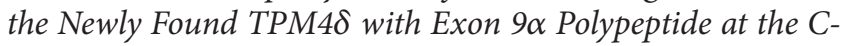
Terminus End. Two-dimensional western blot analyses were performed with commercially available human heart extract with antisarcomeric antitropomyosin (CH1) antibodies. Figure 7(a) shows the Coomassie blue-stained PVDF membrane before western blotting and Figure 7(b) depicts the signals on the X-ray film exposed on the blot after being treated with ECL (see the method section). Figure 7(d) represents the developed X-ray film superimposed on the top of the Coomassie blue-stained PVDF membrane (as in Figures 7(a) and $7(\mathrm{~b})$ ). Nine spots were identified and marked as A, B, C, D, E, F, G, H, and I (Figures 7(a) and 7(b)). The results indicate that there are at least nine detectable $\mathrm{CH} 1$ positive tropomyosin molecules present in the extract from adult human hearts. It is to be noted that each of these spots represents high molecular wt $(32 \mathrm{kD}$ and above) tropomyosin protein. However, we have failed to detect the presence of a low molecular wt CH1-positive tropomyosin protein with a molecular mass $\sim 28 \mathrm{kDa}$ like TPM $4 \delta$ in adult human heart.

In the next step, each of the protein spots that were separated by 2D PAGE and stained by Coomassie dye was excised and washed and the proteins from the gel were treated/processed according to the published protocol (please see the method section) for LS-MS/MS analyses using nanoACQUITY UPLC (Micromass/Waters, Milford, MA) coupled to a Q-TOF Ultima API MS (Micromass/Waters, Milford, MA). The raw data were processed using ProteinLynx Global Server (PLGS, version 2.4) software. Mascot and PLGS database search provided a list of proteins for each gel band. To eliminate false positive results, for the proteins identified by either one peptide or a mascot score lower than 25, we verified the MS/MS spectra that led to identification of a protein. In spot $G$, a total of 53 peptide sequences were identified. As shown in Figure 8, the identified peptides cover $76 \%$ of TPM1 $\alpha$ (accession number gi/63252898) and $38 \%$ of TPM $4 \alpha$ protein (accession number GI: 578833543 ; PREDICTED: tropomyosin alpha- 4 chain isoform $\mathrm{X} 1$; Homo sapiens). It is to be noted that there are not very many differences between TPM $\alpha$ and TPM $4 \alpha$. In this study, we found three peptides, containing a total of three amino acid residues, that are specific for TPM $4 \alpha$ and eight peptides containing eighteen amino acids that are specific for TPM $\alpha$. The remainders of the identified peptides are identical in both isoforms. For TPM1 $\alpha$, peptide in exons 1a, 2, 3, 4, 5, 6, 7, 8, and 9a was identified. For TPM $4 \alpha$, peptides in exons 1a, 8 , and $9 \mathrm{a}$ were identified. Some amino acid changes found in the striated muscle TPM $4 \alpha$ are also found in skeletal muscle TPM $2 \alpha$ (gi I 42476296 isoform, which is also expressed in heart). One of such changes is L19I. Again, ${ }^{252} \mathrm{~T}$ is also present in TPM $2 \alpha$. However, the peptide of the TPM $4 \alpha$ that we have sequenced is quite different from TPM2a peptide. This is true for ${ }^{284} \mathrm{~L}$. The peptide containing ${ }^{284} \mathrm{~L}$ residue from TPM $4 \alpha$ that we have sequenced (as marked with red color) is different from human TPM $2 \alpha$ (gi I42476296). The results indicate the potential expression of TPM $4 \alpha$ protein in human cardiac tissues. 


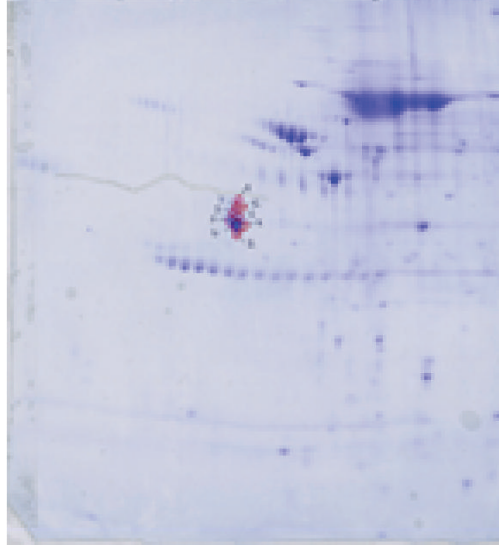

(a)

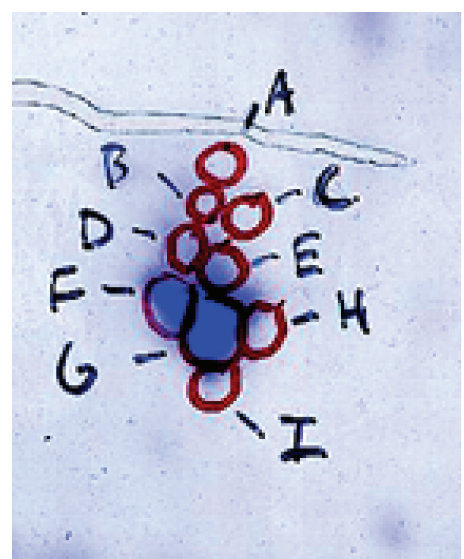

(b)

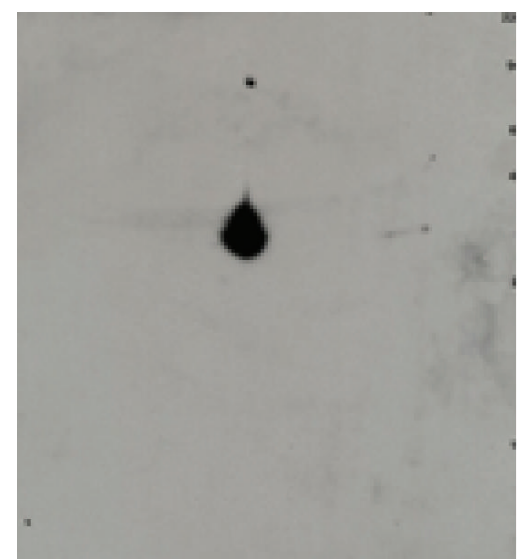

(c)

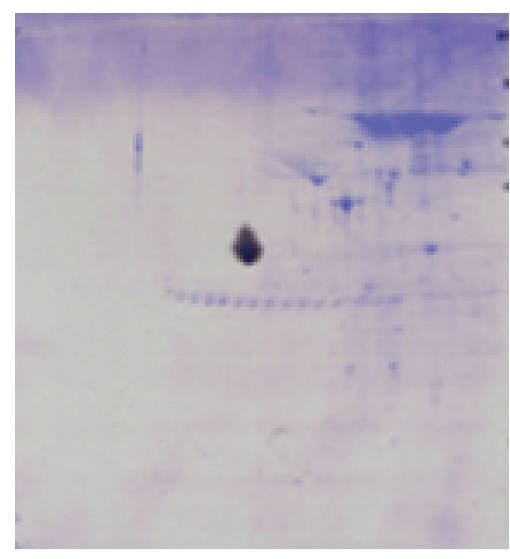

(d)

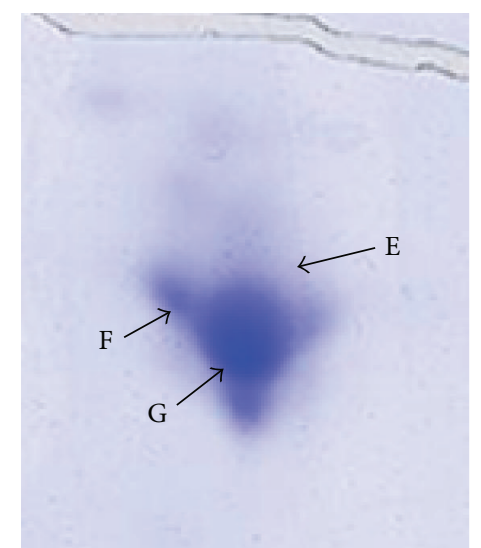

(e)

FIGURE 7: 2D gels of commercially available extracts of human adult heart. (a) The Coomassie stained human adult heart protein across the gel. Seven spots A, B, C, D, E, F, and G were identified, which are not visible clearly. (b) This panel represents the enlarged portion of the gel in (a) and shows clearly A-E spots. (c) The PVDF filter was stained with CH1 monoclonal antibody followed by treatment with secondary antibody as mentioned under Materials and Methods and subsequently treated with ECL and exposed to X-ray film. (d) Developed X-ray film was merged on the top of the Coomassie stained blot. (e) Enlarged nine spots (A-I) were marked on the PVDF filter (as in (a) and (b)) and on the duplicate gel. All the spots were marked and excised and were used for extraction of protein for subsequent mass spectrometric analyses. Extracted peptides from spots E, F, and G were analyzed for mass spectrometry as described in the method section.

\section{Discussion}

In this study, we have cloned and sequenced cDNAs of two novel TPM4 isoforms using RNA from human hearts (Figures 1-3); one is the sarcomeric isoform TPM4 $\alpha$ that encodes a protein with 284 amino acids and the other known as TPM $4 \delta$ encodes a protein with 248 amino acids (Figures 1 and 4). The transcripts of these two isoforms are expressed in fetal heart, adult heart, and skeletal muscle. The expression level is somewhat higher in hearts compared to skeletal muscle (Figures 2 and 5). We were unable to detect the expression of TPM $4 \delta$ (a $\sim 28 \mathrm{kD}$ protein) in either adult or fetal hearts by western blot analyses using $\mathrm{CH} 1$ monoclonal antibody that recognizes an epitope in exon 9a. However, $\mathrm{CH} 1$ antibody detected the expression of high molecular weight TPM proteins $(\sim 32 \mathrm{kDa}$ and above $)$ in adult and fetal hearts (Figure 6). One of the limitations in tropomyosin research is the unavailability of isoform specific antibodies. Without them, it is practically impossible to pinpoint whether the TPM $4 \alpha$ protein is present in the cluster of signals at the high molecular wt region $(32-40 \mathrm{kDa})$ as depicted in Figure 6. In order to gain further insight, we have performed 2D western blot analyses with $\mathrm{CH} 1$ antibody. The gel extracted proteins from various spots with positive signal were analyzed by LS-MS/MS. The results indicate that the spot G contains TPM $4 \alpha$ protein along with TPM1 $\alpha$. It is to be noted that we have also found the expression of TPM $1 \kappa$, TPM $2 \alpha$, and TPM $3 \alpha$ in other spots (data not shown). Our future plan is to further confirm the expression of TPM $4 \alpha$ protein in human striated muscles in healthy and diseased ones. We have compared the expression level of TPM $4 \alpha$ transcripts in fetal and adult human hearts and are planning to compare the corresponding protein expression level in fetal and adult human hearts as well. The fact that we found more peptides 


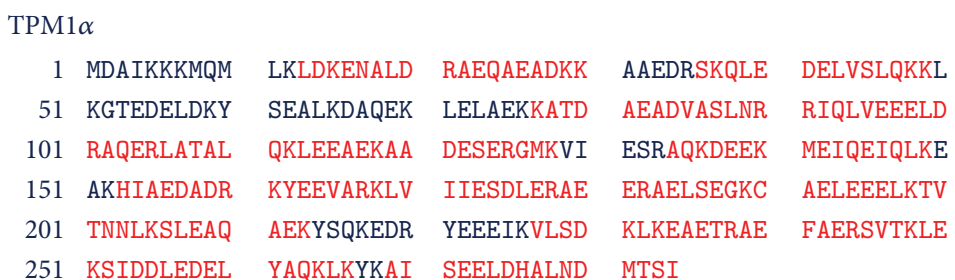

(a)

TPM1 $\alpha$

$\begin{aligned} 1 & \text { MEAIKKKMQM } \\ 51 & \text { KGTEDELDKY } \\ 101 & \text { RAQERLATAL } \\ 151 & \text { AKHIAEEADR } \\ 201 & \text { TNNLKSLEAA } \\ 251 & \text { KTIDDLEDEL }\end{aligned}$

LKLDKENAID RAEQAEADKK SEDLKDAQEK LELTEKKASD QKLEEAEKAA DESERGMKVI KYEEVARKLV ILEGELERAE SEKYSEKEDK YEEEIKLLSD YAQKLKYKAI

\begin{abstract}
AAEDRSKQLE DELVSLQKKL AEADVASLNR RIQLVEEELD ESRAQKDEEK MEIQEIQLKE ERAELSEGKC AELEEELKTV MTSI
\end{abstract}

$\begin{array}{ll}\text { AAEDKCKQVE } & \text { EELTHLQKKL } \\ \text { AEGDVAALNR } & \text { RIQLVEEELD } \\ \text { ENRAMKDEEK } & \text { MEIQEMQLKE } \\ \text { ERAEVSELKC } & \text { GDLEEELKNV } \\ \text { KLKEAETRAE } & \text { FAERTVAKLE } \\ \text { MTSL } & \end{array}$
AEGDVAALNR RIQLVEEELD ENRAMKDEEK MEIQEMQLKE ERAEVSELKC GDLEEELKNV MTSL
AAEDKCKQVE EELTHLQKKL

(b)

Figure 8: Identification of amino acid sequences from the peptides extracted from spot $\mathrm{G}$ after 2D western blot analyses of adult heart extracts with $\mathrm{CH} 1$ antibodies. Red color letters indicate the isolated peptides that have been sequenced by mass spectrometry. (a) TPM1 $\alpha$ and (b) TPM $4 \alpha$. Three amino acid residues in exons 1a, 8, and 9a are different in TPM4 $\alpha$ marked as bold. In case of TPM1 $\alpha$ 76\% (red marked) of the total 284 amino acid residues are being identified. For TPM $4 \alpha$ it is 38\%. It is to be noted that peptide SIDDLEDELYAQKLK in TPM $1 \alpha$ was identified by two precursor ions with $\mathrm{m} / z$ of $594.07(3+)$ and $890.06(2+)$ ions. On the other hand, peptide TIDDLEDELYAQKLK in TPM $4 \alpha$ was identified by one precursor ion with $m / z$ of $888.06(2+)$.

specific to TPMla than TPM4a in spot G is consistent with our bias that there is more of the former than the latter in human cardiomyocytes.

Although the expression of multiple isoforms of tropomyosin has long been known in vertebrates including humans, the precise function of each of the isoforms generated by various TPM genes is not well understood. For example, the expressions of TPM1 $\alpha$ (the sarcomeric isoform of the TPM1 gene) and TPM $2 \alpha$ (sarcomeric isoform of the TPM2 gene) in human hearts have been known for a long time. However, the precise role(s) of the two sarcomeric TPM proteins in cardiac muscle contraction have not been elucidated. More recent published results suggest that TPM1 $\alpha$ makes up about $90 \%$ of the total sarcomeric TPM protein in human hearts. TPM $2 \alpha$ and TPM $1 \kappa$ (another sarcomeric isoform of the TPM1 gene) may constitute the remaining 10 percent of the TPM protein. Peng et al. [25] using top-down mass spectrometry confirmed that TPM $1 \alpha$ constitutes $90 \%$ of the total sarcomeric tropomyosin in human hearts. They also detected a low amount of TPM $2 \alpha$ and TPM $\kappa$ expression in human hearts. There was no mention about the expression of TPM $4 \alpha$ in this paper. Marston et al. also reported the expression of TPM $3 \alpha$ in human heart [26]. These authors reported that the level of expression of TPM1 $\alpha$ and TPM1 $\kappa$ was $95 \%$ and $4 \%$, respectively, of the total sarcomeric tropomyosin in human hearts. In addition, a low level of expression of TPM $2 \alpha$, TPM $3 \alpha$, and TPM $1 \beta$ (smooth muscle type tropomyosin) was also detected. Again, there was no mention about the expression of TPM $4 \alpha$.

Researchers from different laboratories using transgenic mouse models have delineated the tentative function of TPM $1 \alpha$ and TPM $2 \alpha$ in mammalian hearts [27-29]. In the adult healthy mouse heart the protein expression level of
TPM $2 \alpha$ is less than $2 \%$. When there was $55-60 \%$ of TPM $2 \alpha$ present in the myocardium of transgenic mouse heart, the time of relaxation, maximum rate of relaxation, and sensitivity to calcium changed significantly. Further altering of TPM $2 \alpha$ to an even higher level in the heart of transgenic mice will cause postnatal death in between 10 and 14 days [27-29]. TPM $3 \alpha$ is not expressed in mouse hearts [4]. High ectopic expression level of TPM $3 \alpha(40-60 \%)$ can lead to hyperdynamic effect on systolic and diastolic function and decreased calcium sensitivity [30]. As TPM $3 \alpha$ is not expressed in mouse heart, it is not possible to perform knockout/knockdown experiments for TPM $3 \alpha$. Again, overexpression of TPM $1 \kappa$ in a cardiac-specific manner in transgenic mouse leads to a dilated cardiomyopathy (DCM) like syndrome. Interestingly, the expression level of TPM1 $\kappa$ protein has been found to be significantly higher in hearts from DCM and heart failure patients. The functional analysis of TPM1 $\kappa$ provides a possible mechanism for the consequences of the TPM isoform switch observed in DCM and heart failure patients [31].

The functional aspect of TPM $3 \alpha$ in human cardiac tissues is not known yet. Our finding of the potential expression of TPM $4 \alpha$ in human heart muscles makes the situation more complicated. The most important, as well as most difficult, question yet to be addressed is whether minute expression of the sarcomeric TPM proteins such as TPM $1 \kappa$, TPM $2 \alpha$, TPM $3 \alpha$, and TPM $4 \alpha$ plays any significant role in cardiac contractility and/or cardiac function.

As rodents with truncated TPM4 genes are not capable of producing sarcomeric TPM $4 \alpha$ protein, the in vivo function of TPM $4 \alpha$ using knockdown/knockout technology is not possible. However, one can generate transgenic mouse ectopically overexpressing human TPM $4 \alpha$ protein in a cardiac 
specific manner and find out whether ectopic expression is altering the cardiac morphology and/or cardiac contractility. Another approach researchers have used for assigning the function of a protein is to look for its association with any human disease(s). For example, various TPM1 and TPM2 mutations have been implicated in hypertrophic cardiomyopathy (HCM) including familial hypertrophic cardiomyopathy (FHC) in humans [31]. Similarly, several missense mutations in TPM2 and TPM3 have been implicated in nemaline myopathy that suggest the functional importance of these genes or particular isoform in cellular function. To the best of our knowledge no mutation in TPM4 gene has been implicated in any diseases of striated muscles in humans. However, one cannot rule out that this possibility was not considered before because of the belief that the TPM4 gene in humans, as in rodents, does not produce the sarcomeric isoform TPM $4 \alpha$.

\section{Competing Interests}

The authors declare that there is no conflict of interests regarding the publication of this paper.

\section{Acknowledgments}

The work was supported by a grant from the Department of Medicine and Barbara Kopp Cancer Research Fund to Bernard J. Poiesz. The authors would like to thank Dr. Costal C. Darie, Associate Professor, Clarkson University, Potsdam, New York, for his kind help in explaining the details of LCMS/MS analysis. Authors are thankful to Ms. Lori Spicer for her assistance for the preparation of the manuscript.

\section{References}

[1] P. Gunning, G. O’Neill, and E. Hardeman, "Tropomyosinbased regulation of the actin cytoskeleton in time and space," Physiological Reviews, vol. 88, no. 1, pp. 1-35, 2008.

[2] J. P. Lees-Miller and D. M. Helfman, "The molecular basis for tropomyosin isoform diversity," BioEssays, vol. 13, no. 9, pp. 429-437, 1991.

[3] S. V. Perry, "Vertebrate tropomyosin: distribution, properties and function," Journal of Muscle Research and Cell Motility, vol. 22, no. 1, pp. 5-49, 2001.

[4] K. Pieples and D. F. Wieczorek, "Tropomyosin 3 increases striated muscle isoform diversity," Biochemistry, vol. 39, no. 28, pp. 8291-8297, 2000.

[5] M. F. Pittenger, J. A. Kazzaz, and D. M. Helfman, "Functional properties of non-muscle tropomyosin isoforms," Current Opinion in Cell Biology, vol. 6, no. 1, pp. 96-104, 1994.

[6] G. Schevzov, S. P. Whittaker, T. Fath, J. J.-C. Lin, and P. W. Gunning, "Tropomyosin isoforms and reagents," BioArchitecture, vol. 1, no. 4, pp. 135-164, 2011.

[7] M. A. Geeves, S. E. Hitchcock-DeGregori, and P. W. Gunning, "A systematic nomenclature for mammalian tropomyosin isoforms," Journal of Muscle Research and Cell Motility, vol. 36, no. 2, pp. 147-153, 2015.
[8] D. E. Fleenor, K. H. Hickman, G. J. Lindquester, and R. B. Devlin, "Avian cardiac tropomyosin gene produces tissuespecific isoforms through alternative RNA splicing," Journal of Muscle Research and Cell Motility, vol. 13, no. 1, pp. 55-63, 1992.

[9] S. Hardy, N. Thézé, D. Lepetit, M.-R. Allo, and P. Thiebaud, "The Xenopus laevis TM-4 gene encodes non-muscle and cardiac tropomyosin isoforms through alternative splicing," Gene, vol. 156, no. 2, pp. 265-270, 1995.

[10] B. J. Spinner, R. W. Zajdel, M. D. McLean et al., "Characterization of a TM-4 type Tropomyosin that is essential for myofibrillogenesis and contractile activity in embryonic hearts of the Mexican axolotl," Journal of Cellular Biochemistry, vol. 85, no. 4, pp. 747-761, 2002.

[11] A. Thomas, S. Rajan, H. L. Thurston et al., "Expression of a novel tropomyosin isoform in axolotl heart and skeletal muscle," Journal of Cellular Biochemistry, vol. 110, no. 4, pp. 875-881, 2010.

[12] H. L. Thurston, S. Prayaga, A. Thomas et al., "Expression of Nkx2.5 in wild type, cardiac mutant, and thyroxine-induced metamorphosed hearts of the mexican axolotl," Cardiovascular Toxicology, vol. 9, no. 1, pp. 13-20, 2009.

[13] M. W. Pfaffl, "A new mathematical model for relative quantification in real-time RT-PCR," Nucleic Acids Research, vol. 29, no. 9, article e45, pp. 2002-2007, 2001.

[14] K. J. Livak and T. D. Schmittgen, "Analysis of relative gene expression data using real-time quantitative PCR and the $2^{-\Delta \Delta \mathrm{C}_{\mathrm{T}}}$ method," Methods, vol. 25, no. 4, pp. 402-408, 2001.

[15] J. S. Yuan, A. Reed, F. Chen, and C. N. Stewart Jr., "Statistical analysis of real-time PCR data," BMC Bioinformatics, vol. 7, article 85, 2006.

[16] C. Nan, S. Dube, A. Matoq et al., "Expression of sarcomeric tropomyosin in striated muscles in axolotl treated with Shz-1, a small cardiogenic molecule," Cardiovascular Toxicology, vol. 15, no. 1, pp. 29-40, 2015.

[17] S. Dube, L. Panebianco, A. A. Matoq et al., "Expression of TPM1 $\kappa$, a novel sarcomeric isoform of the TPM1 gene, in mouse heart and skeletal muscle," Molecular Biology International, vol. 2014, Article ID 896068, 9 pages, 2014.

[18] P. H. O'Farrell, "High resolution two-dimensional electrophoresis of proteins," The Journal of Biological Chemistry, vol. 250, no. 10, pp. 4007-4021, 1975.

[19] A. Burgess-Cassler, J. J. Johansen, D. A. Santek, J. R. Ide, and N. C. Kendrick, "Computerized quantitative analysis of coomassieblue-stained serum proteins separated by two-dimensional electrophoresis," Clinical Chemistry, vol. 35, no. 12, pp. 22972304, 1989.

[20] J. Wang, D. K. Dube, J. White, Y. Fan, J. M. Sanger, and J. W. Sanger, "Clock is not a component of Z-bands," Cytoskeleton, vol. 69, no. 12, pp. 1021-1031, 2012.

[21] A. Shevchenko, M. Wilm, O. Vorm, and M. Mann, "Mass spectrometric sequencing of proteins from silver-stained polyacrylamide gels," Analytical Chemistry, vol. 68, no. 5, pp. 850858, 1996.

[22] C. C. Darie, K. Deinhardt, G. Zhang, H. S. Cardasis, M. V. Chao, and T. A. Neubert, "Identifying transient protein-protein interactions in EphB2 signaling by blue native PAGE and mass spectrometry," Proteomics, vol. 11, no. 23, pp. 4514-4528, 2011.

[23] I. Sokolowska, A. G. Woods, M. A. Gawinowicz, U. Roy, and C. C. Darie, "Identification of potential tumor differentiation factor (TDF) receptor from steroid-responsive and steroidresistant breast cancer cells," The Journal of Biological Chemistry, vol. 287, no. 3, pp. 1719-1733, 2012. 
[24] D. S. Spellman, K. Deinhardt, C. C. Darie, M. V. Chao, and T. A. Neuebrt, "Stable isotopic labeling by amino acids in cultured primary neurons: application to brain-derived neurotrophic factor-dependent phosphotyrosine-associated signaling," Molecular and Cellular Proteomics, vol. 7, no. 6, pp. 10671076, 2008.

[25] Y. Peng, D. Yu, Z. Gregorich et al., "In-depth proteomic analysis of human tropomyosin by top-down mass spectrometry," Journal of Muscle Research and Cell Motility, vol. 34, no. 3, pp. 199-210, 2013.

[26] S. B. Marston, O. Copeland, A. E. Messer et al., "Tropomyosin isoform expression and phosphorylation in the human heart in health and disease," Journal of Muscle Research and Cell Motility, vol. 34, no. 3-4, pp. 189-197, 2013.

[27] M. Muthuchamy, I. L. Grupp, G. Grupp et al., "Molecular and physiological effects of overexpressing striated muscle $\beta$ tropomyosin in the adult murine heart," The Journal of Biological Chemistry, vol. 270, no. 51, pp. 30593-30603, 1995.

[28] M. Muthuchamy, L. Pajak, P. Howles, T. Doetschman, and D. F. Wieczorek, "Developmental analysis of tropomyosin gene expression in embryonic stem cells and mouse embryos," Molecular and Cellular Biology, vol. 13, no. 6, pp. 3311-3323, 1993.

[29] M. Muthuchamy, P. Rethinasamy, and D. F. Wieczorek, "Tropomyosin structure and function: new insights," Trends in Cardiovascular Medicine, vol. 7, no. 4, pp. 124-128, 1997.

[30] K. Pieples, G. Arteaga, R. John Solaro et al., "Tropomyosin 3 expression leads to hypercontractility and attenuates myofilament length-dependent $\mathrm{Ca}^{2+}$ activation," American Journal of Physiology-Heart and Circulatory Physiology, vol. 283, no. 4, pp. H1344-H1353, 2002.

[31] S. Rajan, G. Jagatheesan, C. N. Karam et al., "Molecular and functional characterization of a novel cardiac-specific human tropomyosin isoform," Circulation, vol. 121, no. 3, pp. 410-418, 2010. 

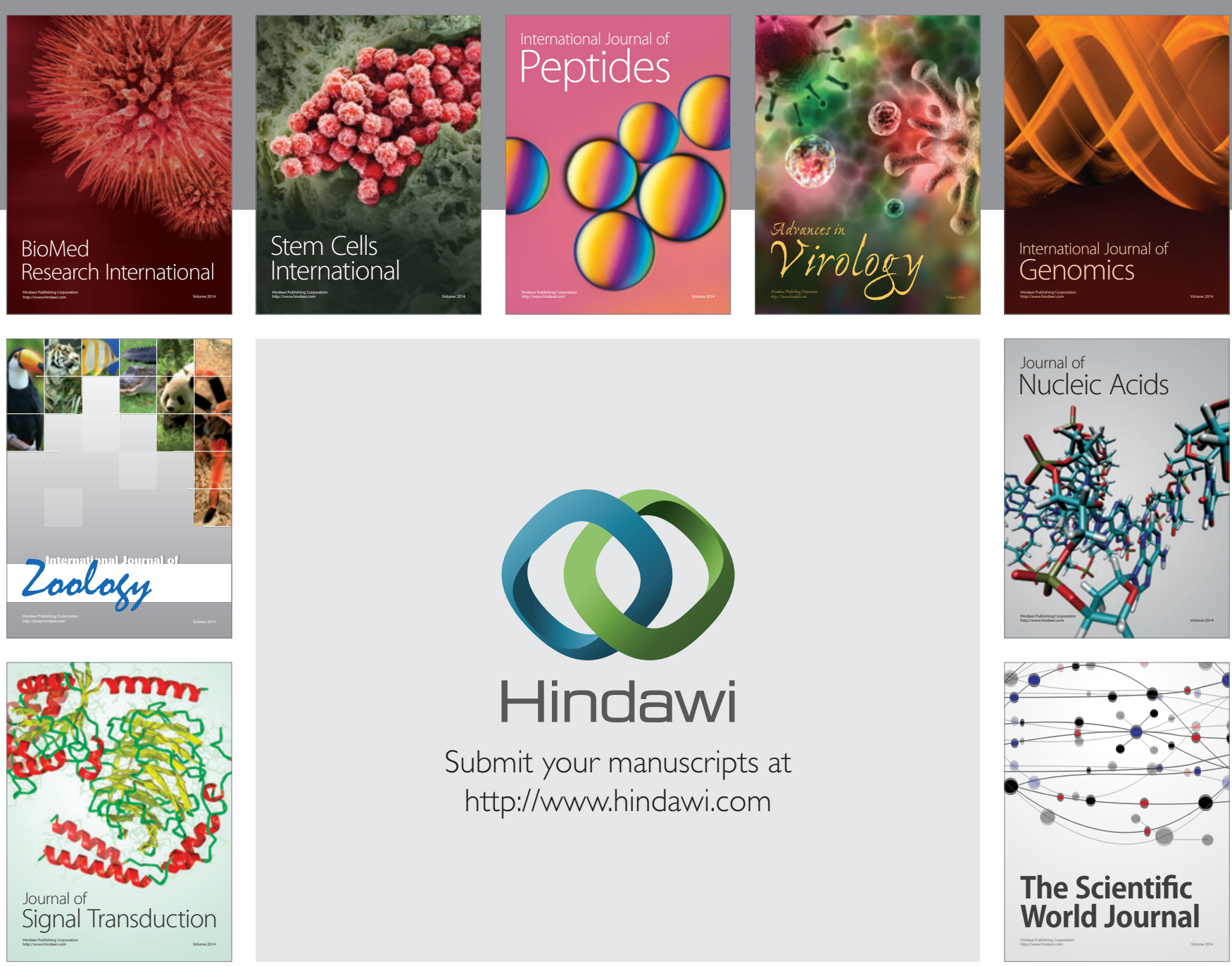

Submit your manuscripts at

http://www.hindawi.com
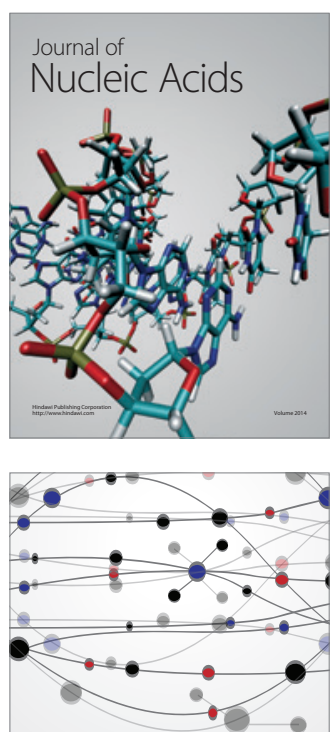

The Scientific World Journal
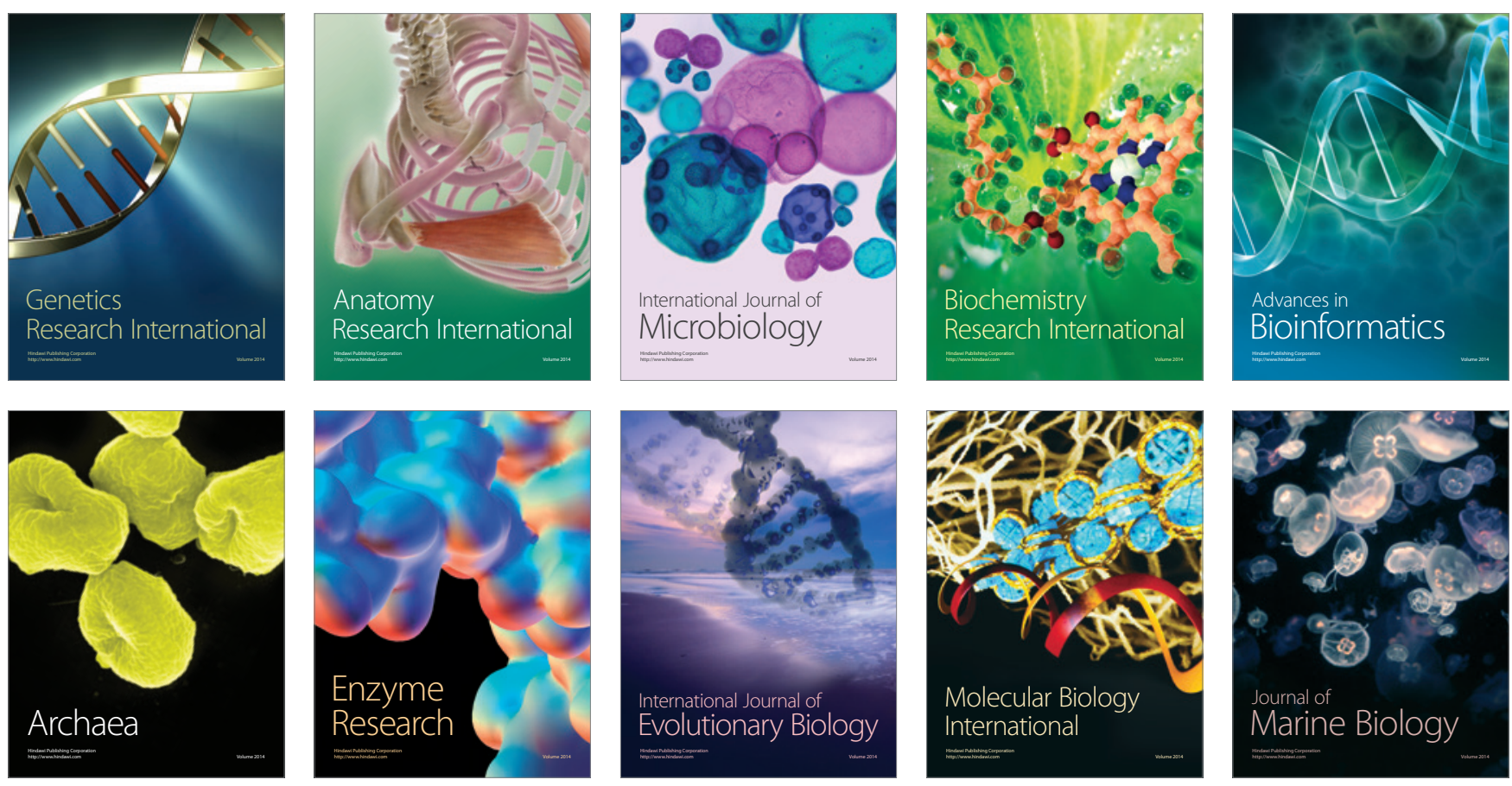